\title{
Research on the Relationship between China's Economic Policy Uncertainty and Stock Market
}

\author{
Donghai Zhou, Yuanying Jiang \\ College of Science, Guilin University of Technology, Guilin, China \\ Email: donghai@glut.edu.cn
}

How to cite this paper: Zhou, D. H., \& Jiang, Y. Y. (2020). Research on the Relationship between China's Economic Policy Uncertainty and Stock Market. Journal of Financial Risk Management, 9, 462-479. https://doi.org/10.4236/jfrm.2020.94025

Received: November 27, 2020

Accepted: December 8, 2020

Published: December 11, 2020

Copyright $\odot 2020$ by author(s) and Scientific Research Publishing Inc. This work is licensed under the Creative Commons Attribution International License (CC BY 4.0).

http://creativecommons.org/licenses/by/4.0/ (c) (i) Open Access

\begin{abstract}
Under the cycle of increasing global uncertainty, China's stock market is facing unprecedented challenges. This article explains the interaction mechanism between China's economic policy uncertainty (EPU) and stock market prices, and uses monthly data from January 2005 to October 2020 to conduct empirical research, and finally conducts a robustness test. The results show that there is a long-term co-integration relationship between China's EPU and China's stock market prices, and they are Granger causality. On the basis of the above inspection, through impulse response analysis and variance decomposition methods, it is found that the impact of China's stock market prices on the EPU has directional changes over time, and the impact of China's stock market price rise will cause China's EPU decline, the period of decline lasted for 4 months, after which the EPU gradually increased. Conversely, the increase of China's EPU will have a significant inhibitory effect on China's stock market prices, and it will have a lagging and long-term persistence. On the whole, China's EPU has a very severe impact on China's stock market. It is recommended to pay attention to the transmission of economic policy formulations to the stock market's sentiment to reduce the impact of economic policies on the stability of the stock market.
\end{abstract}

\section{Keywords}

Economic Policy Uncertainty, Stock Market, Vector Autoregressive Model, Impulse Response, Variance Decomposition

\section{Introduction}

The global financial crisis has caused severe damage to the stock markets of various countries. Many countries and regions quickly made a series of rescue policies to stabilize the stock market, quickly stimulate the economy, and promote 
the development of the market in a positive direction. China has also adopted strong fiscal policies to ease the downward pressure on the economy brought about by the financial crisis, including increasing government investment and promoting industrial revitalization plans. These policies have also released China from the financial crisis as quickly as possible. At present, the international economic and financial structure is in the process of continuous and in-depth adjustment, the external economic environment is becoming more and more complex, and the internal economic environment is increasingly dependent on economic policies. The situation of internal and external troubles has led to the gradual increase in the frequency and intensity of the formulation and implementation of economic policies in various countries, and economic policy uncertainty (Economic Policy Uncertainty, EPU) is getting deeper. In a nutshell, EPU refers to the possibility of policy authorities adjusting the original policy or issuing new policies, which is mainly reflected in the inability of economic entities to accurately predict the specific measures the government will take to implement these economic policies. Reform and opening up have transformed China's economic policy from a planned economic policy to a market-based economic policy. However, due to the lack of previous reform experience, the policy-making method of "crossing the river by feeling the stones" has increased policy uncertainty. When EPU increases, "financial anomalies" are more likely to occur. As the stock market is an important part of the financial market, in order to effectively deal with the financial anomalies in China's stock market, it is of great significance to study the relationship between the stock market and EPU in China.

At present, there are more and more literatures about the relationship between EPU and stock market price, but the research conclusions of relevant literatures are not consistent. For example, scholars have different conclusions on whether there is a relationship between EPU and the stock market. Wu et al. (2016) used the Bootstrap panel Granger test method and found that there was no significant correlation between China's stock price index and EPU. However, Li et al. (2016) found a bidirectional causal relationship between the two through Bootstrap scrolling window method. Wang et al. (2018) found that China's EPU has a significant positive impact on the return of the stock market, and believed that EPU is a very important pricing factor for China's stock market. Chiang (2019) research shows that an increase in EPU will lead to a decrease in excess stock returns. Chen et al. (2017) found that stock returns will increase with the increase of EPU, but stock risks also increase. Bernal et al. (2016) pointed out that the increase of EPU in the euro area will affect the bond market, while the EPU in the United States also increases the risk transmission of the euro area sovereign bond market. Regarding whether the EPU of a certain country can cause common fluctuations in the stock markets of multiple countries, $\mathrm{Li}$ and Peng (2017) found that a larger increase or a larger decline in the EPU of the United States will reduce the subsequent common fluctuations between the 
Chinese and American stock markets. Regarding the impact of EPU on the stock price risk premium, academic circles have also carried out research. Pástor and Veronesi (2013) found that EPU has the effect of increasing the risk premium of stock prices by establishing a general equilibrium model. This uncertainty reduces the value of the government's invisible protection for the market and makes the stock market more volatile. Lin et al. (2014) examined the impact of EPU on asset pricing based on the Chinese stock market and found that China's EPU has a positive risk premium. Jia et al. (2019) studied the pre-announcement premium in the stock market and found that the reason for the pre-announcement premium was that investors received premium compensation for policy uncertainty in advance. With the deepening of research, some scholars believe that it is necessary to distinguish between the short-term and long-term effects of economic uncertainty on stock prices. Bahmani-Oskooee and Saha (2019) analyzed relevant data of 13 countries and found that policy uncertainty had a significant negative impact on stock prices in the short term, but not in the long term.

Since EPU cannot be directly observed, scholars from various countries use different methods to measure it. Sialm (2005) used government tax change data to determine the uncertainty in asset pricing, and empirically analyzed the measured uncertainty with the overall stock market valuation, and concluded that the two are negatively correlated. Dzielinski (2012) used a grid search method to measure the EPU in the United States, and found that EPU will cause a decrease in the return rate of the U.S. stock market and an increase in volatility. In addition, the VIX index (a volatility index constructed based on the S\&P 500 index) is often used to measure uncertainty (Bloom, 2009), but it is found to be unsuitable for a broad economic environment. In addition, some scholars mainly use a specific event as a measurement, such as the change of office or government election (Goodell and Vähämaa, 2013), but it lacks applicability and continuity. The EPU index constructed by Baker et al. (2016) is currently a more popular measurement index. On this basis, Huang and Luk (2019) used ten newspapers issued by major cities in China to conduct text mining to analyze the Chinese economy. The capture of China Economic Policy Uncertainty (CNEPU) is more representative and objective. Therefore, the CNEPU index in this article adopts the version compiled by Huang and Luk (2019).

When most scholars discuss the relationship between EPU and stock market prices, they only analyze the impact of EPU on stock market prices, without considering whether stock market performance will affect EPU. According to the research of Antonakakis et al. (2013), the performance of the stock market will in turn affect EPU. Because government policy makers sometimes have to adjust policies to cope with the increased volatility of the stock market, the greater the volatility of the stock market, the greater the uncertainty of economic policies. Based on the above analysis, this paper selects China's EPU and stock market data as the research sample, and empirically analyzes the relationship between EPU and stock market prices by using the vector autoregression (VAR) method. 


\section{Empirical Analysis}

\subsection{Data Sources and Descriptive Analysis}

First of all, using the Shanghai and Shenzhen Stock Exchange's CSI300 Index as a proxy indicator of China's stock market prices, the CSI300 Index can reflect the overall trend of the Shanghai and Shenzhen markets and has a strong coverage. The China' EPU Index uses the version compiled by Huang and Luk (2019). The data selection interval is the monthly data from January 2005 to October 2020. The number of observations for the two variables is $190\left(15^{\star} 12+10=190\right)$.

Table 1 shows the descriptive statistical analysis of the CNEPU and China stock market price (CSI300) series. The results in the table show that the average value of CNEPU is 131.5531, the maximum value is 238.3172 , the minimum value is 52.19576 , and the standard deviation is 33.07231 . The mean value of CSI300 is 2984.548, the maximum value is 5688.540 , the minimum value is 855.9500, and the standard deviation is 1028.202 . This shows that the two fluctuate greatly during the sample period. From the comparison of standard deviations, the standard deviation of CSI300 is larger, indicating that the dispersion of CSI300 is higher. It can be seen from the skewness and kurtosis values and the JB normality test that the p-values in the JB normality tests of CNEPU and CSI300 are significantly greater than the $5 \%$ significance level, and the null hypothesis of normal distribution cannot be rejected.

Figure 1 is the time chart of the CNEPU and CSI300 series. By observing the

Table 1. Descriptive statistical analysis of CNEPU and CSI300.

\begin{tabular}{ccccccccc}
\hline Variable & Mean & Maximum & Minimum & Std. Dev. & Skewness & Kurtosis & $\begin{array}{c}\text { Jarque-Bera } \\
\text { (Probability) }\end{array}$ \\
\hline CNEPU & 131.553 & 238.317 & 52.196 & 33.072 & 0.078 & 3.264 & $\begin{array}{c}0.746907 \\
(0.688353)\end{array}$ \\
& & & & & & & & \\
CSI300 & 2984.548 & 5688.540 & 855.950 & 1028.202 & -0.159 & 2.906 & $\begin{array}{c}0.869574 \\
(0.647402)\end{array}$
\end{tabular}

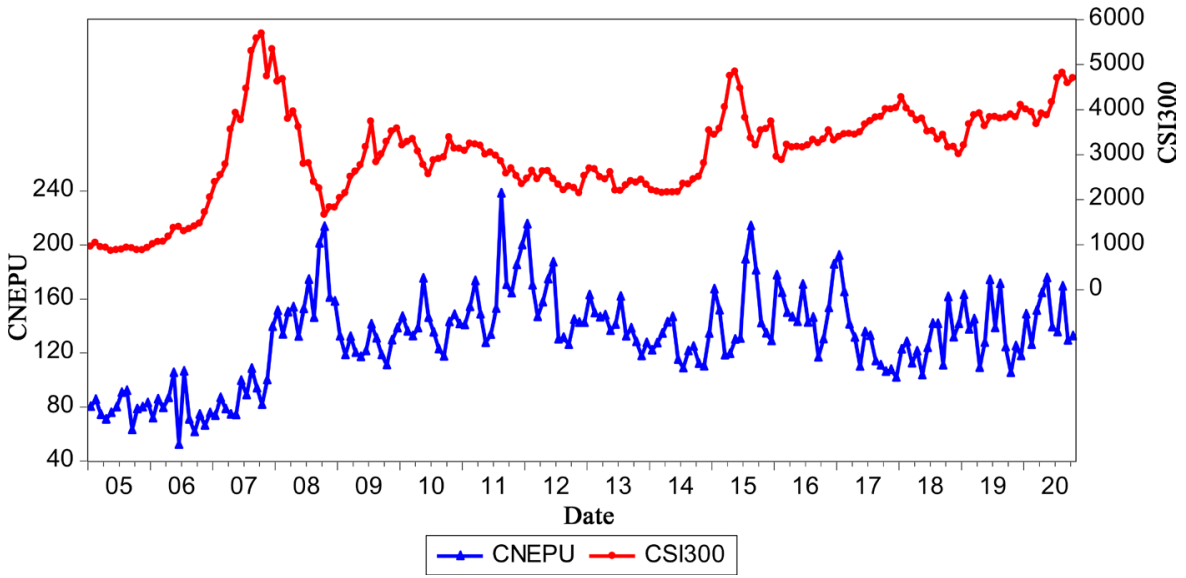

Figure 1. Original sequence chart of China's EPU and China's stock market ${ }^{1}$.

${ }^{1}$ The data of CNEPU comes from: https://economicpolicyuncertaintyinchina.weebly.com/;

The data of CSI300 comes from: https://cn.investing.com/. 
time sequence charts, it can be seen that similar fluctuations occur during the research phase of the two sequences, which preliminarily indicates that they have a certain correlation. Specifically, the two changes in the research phase fluctuated greatly. Before 2008, the CNEPU and CSI300 as a whole showed a trend of upward volatility. Due to the spread of the subprime mortgage crisis in the United States and the impact of the escalation of austerity policies, CSI300 fell rapidly after reaching its peak in October 2007 and began to enter a serious bear market, while the CNEPU continued to fluctuate and began to decline after reaching a small peak in October 2008. From January 2014 to May 2015, the abundant capital provided sufficient fund support for the rise of the stock market. During this period, CSI300 continued to rise and CNEPU also showed an upward trend.

\subsection{Cointegration Test and Granger Causality}

In order to reduce the heteroscedasticity of the two sequence data, the logarithmic processing of the two column data is carried out. The unit root test is performed on the LNCNEPU and LNCSI300 sequences, and the unit root test method adopts ADF test and PP test. According to LNCNEPU and LNCSI300 sequence, difference sequence and AIC criterion, the type of unit root test is determined. The lag order selection criterion of ADF test is AIC, and the lag order selection criterion of PP test is Bartlett kernel. It can be seen from Table 2 that the ADF statistical values of LNCNEPU and LNCSI300 are -2.437027 and -2.587546 , respectively, and the statistical values of PP test are 0.528331 and -2.492834 respectively. The $\mathrm{p}$-values of ADF test and PP test are both greater than the $1 \%$ significance level, so the null hypothesis of the existence of unit root could not be rejected by judging both of them. After differential processing of LNCNEPU and LNCSI300, the ADF statistical values of the sequence after difference are -11.77687 and -4.148908 , and the statistical values of PP test are -34.90446 and -12.55909 , respectively. The $\mathrm{p}$-values of ADF test and PP test are less than $1 \%$ significance level, and the null hypothesis of unit root is rejected. Therefore, both LNCNEPU and LNCSI300 sequences are stationary sequences after first-order difference, that is, they are subject to first-order integral I (1) process.

Table 2. ADF unit root test.

\begin{tabular}{cccccc}
\hline \multirow{2}{*}{ Variables } & \multicolumn{2}{c}{ ADF test } & \multicolumn{2}{c}{ PP test } & Test result \\
\cline { 2 - 5 } & ADF statistics & p-Value & PP statistics & p-Value & \\
\hline LNCNEPU & -2.437027 & 0.1331 & 0.528331 & 0.8292 & Unstable \\
D(LNCNEPU $)$ & $-11.77687^{* * *}$ & 0.0000 & $-34.90446^{* * *}$ & 0.0001 & Stable \\
LNCSI300 & $-2.587546^{*}$ & 0.0973 & -2.492834 & 0.1188 & Unstable \\
D(LNCSI300) & $-4.148908^{* * *}$ & 0.0011 & $-12.55909^{* * *}$ & 0.0000 & Stable \\
\hline
\end{tabular}

Note: ${ }^{*}{ }^{* *},{ }^{* *}$ mean significant at the level of $10 \%, 5 \%$, and $1 \%$ respectively. 
If the single integral order of the linear combination of several time series is less than the single integral order of its components, then it is said that there is cointegration between these sequences. The Johanson method allows multiple cointegration relationships, so it is more widely used than the Engle-Granger test. There are two Johanson tests: based on trace test or eigenvalue, this article uses two tests of Johanson method. The results of the ADF and PP unit root tests in Table 2 show that the two variables are single-integrated in the same order, so the conditions for the co-integration test are met. Therefore, the next step is to perform a co-integration test to determine whether there is a long-term cointegration relationship between the two. Table 3 and Table 4 are the cointegration test results of LNCNEPU and LNCSI300 sequences respectively, Table 3 is the trace test, and Table 4 is the maximum eigenvalue test. It can be seen from the two test results that when the null hypothesis is that there is no cointegration relationship and at most one cointegration relationship, the statistics of the trace test and the maximum eigenvalue test are both higher than the statistics of the $5 \%$ significance level, and the p-values are both less than 5\% significance level, it can be considered that there is a long-term cointegration relationship between LNCNEPU and LNCSI300 sequences. Therefore, the following LNCNEPU and LNCSI300 sequences can be used to build a VAR model.

To illustrate the dynamic correlation between LNCNEPU and LNCSI300 and to determine whether variables can predict other variables, Granger causality test is used to consider the following time series models:

$$
y_{t}=\gamma+\sum_{m=1}^{p} \alpha_{m} y_{t-m}+\sum_{m=1}^{p} \beta_{m} x_{t-m}+\varepsilon_{t}
$$

The null hypothesis of this expression $H_{0}: \beta_{1}=\cdots=\beta_{p}=0$. If the null hypothesis is rejected, then $x$ is the Granger cause for $y$. If the positions of $x$ and $y$ are interchanged, then it can be concluded whether $y$ is the Granger cause of $x$ (Tsay, 2005). Table 5 shows the Granger causality test between LNCNEPU and LNCSI300. It can be seen from Table 5 that at the $5 \%$ significance level, LNCSI300 is the Granger cause of LNCNEPU, that is, the Chinese stock market

Table 3. Unrestricted cointegration rank test (trace).

\begin{tabular}{ccccc}
\hline Hypothesized No. of CE(s) & Eigenvalue & Trace Statistic & 0.05 Critical Value & Prob. \\
\hline None & 0.167013 & $39.94938^{* * *}$ & 15.49471 & 0.0000 \\
At most 1 & 0.029321 & $5.594751^{* *}$ & 3.841466 & 0.0180 \\
\hline
\end{tabular}

Note: ${ }^{*}{ }^{* *},{ }^{* *}$ mean significant at the level of $10 \%, 5 \%$, and $1 \%$ respectively.

Table 4. Unrestricted cointegration rank test (maximum eigenvalue).

\begin{tabular}{ccccc}
\hline Hypothesized No. of CE(s) & Eigenvalue & Max-EigenStatistic & 0.05 Critical Value & Prob. \\
\hline None & 0.167013 & $34.35462^{\star * *}$ & 14.26460 & 0.0000 \\
At most 1 & 0.029321 & $5.594751^{\star *}$ & 3.841466 & 0.0180 \\
\hline
\end{tabular}

Note: ${ }^{*}{ }^{* *},{ }^{* *}$ mean significant at the level of $10 \%, 5 \%$, and $1 \%$ respectively. 
Table 5. Granger causality test.

\begin{tabular}{cll}
\hline Null Hypothesis: & F-Statistic & Prob. \\
\hline LNCSI300 does not Granger Cause LNCNEPU & $13.7591^{* * *}$ & 0.0003 \\
LNCNEPU does not Granger Cause LNCSI300 & $6.36813^{* *}$ & 0.0125 \\
\hline
\end{tabular}

Note: ${ }^{*}, * * * *$ mean significant at the level of $10 \%, 5 \%$, and $1 \%$ respectively.

price is the Granger cause of China's EPU; and LNCNEPU is also the Granger cause of LNCSI300, That is, the China's EPU is also the Granger cause for China's stock market prices. To sum up, China's EPU and the price of China's stock market are Granger causes for each other.

Furthermore, the cross-correlation matrix (CCM) and multivariate portmanteau test are used to explore the relationship between autocorrelation, cross-correlation and lag order correlation between LNCNEPU and LNCSI300 sequences. First, the theory of CCM method is given. Given sample $\left\{Y_{t}\right\}_{t=1}^{T}$,

$Y_{t}=\left(\operatorname{LNCNEPU}_{t}, \mathrm{LNCSI}_{300}\right)^{\prime}, T$ is the sample size, in this paper, $T=190$, and the sample mean and covariance matrix are obtained:

$$
\hat{u}_{Y}=\frac{1}{T} \sum_{t=1}^{T} Y_{t}, \hat{\Gamma}_{0}=\frac{1}{T-1} \sum_{t=1}^{T}\left(Y_{t}-\hat{u}_{Y}\right)\left(Y_{t}-\hat{u}_{Y}\right)^{\prime}
$$

The sample cross-covariance matrix for the lagging I period is defined as:

$$
\hat{\Gamma}_{l}=\frac{1}{T-1} \sum_{t=l+1}^{T}\left(Y_{t}-\hat{u}_{Y}\right)\left(Y_{t-l}-\hat{u}_{Y}\right)^{\prime}
$$

Then the CCM with lag $l$ is defined as:

$$
\hat{\rho}_{l}=\hat{D}^{-1} \hat{\Gamma}_{l} \hat{D}^{-1}
$$

among them, $\hat{D}=\operatorname{diag}\left\{\hat{\gamma}_{0,11}^{1 / 2}, \cdots, \hat{\gamma}_{0,22}^{1 / 2}\right\}, \hat{\gamma}_{0, i i}$ is the $(i, i)$ element of $\hat{\Gamma}_{0}$.

Secondly, the theory of multivariate portmanteau test method is given. A basic test in multivariate time series analysis is to examine the existence of linear dynamic dependence in the data. This is equivalent to testing the null hypothesis $H_{0}: \rho_{1}=\cdots=\rho_{m}=0$ and the alternative hypothesis $H_{1}: \rho_{i} \neq 0$. For some $i$ satisfying $1 \leq i \leq m, m$ is a positive integer. If the variable fails to pass the multivariate portmanteau test, it indicates that the linear correlation between variables is weak. At this point, the results obtained by establishing the VAR model are biased (Tsay, 2013). However, most of the empirical literatures on the VAR model omit this step, which is not desirable. The multivariate portmanteau test statistic is defined as:

$$
Q_{k}(m)=T^{2} \sum_{l=1}^{m} \frac{1}{T-l} \operatorname{tr}\left(\hat{\Gamma}_{l}^{\prime} \hat{\Gamma}_{0}^{-1} \hat{\Gamma}_{l} \hat{\Gamma}_{0}^{-1}\right)
$$

$T$ is the sample size, $\operatorname{tr}\left(\hat{\Gamma}_{l}^{\prime} \hat{\Gamma}_{0}^{-1} \hat{\Gamma}_{l} \hat{\Gamma}_{0}^{-1}\right)$ is the trace of the matrix $\hat{\Gamma}_{l}^{\prime} \hat{\Gamma}_{0}^{-1} \hat{\Gamma}_{l} \hat{\Gamma}_{0}^{-1}$, $\hat{\Gamma}_{0}$ and $\hat{\Gamma}_{l}$ are the sample covariance matrix and the cross covariance matrix respectively, and the statistic $Q_{k}(m)$ asymptotically obeys the chi-square distribution with $(m-p) k^{2}$ degrees of freedom.

Table 6 shows the multiple portmanteau test, and the results show that 
CNEPU and CSI300 have obvious autocorrelation and cross-correlation at the significance level of $1 \%$. Furthermore, CCM results in the figure show that the correlation coefficients of the two time series with the lag period from 1 to 12 are relatively high, indicating that there is a long-term correlation between CNEPU and CSI300.

\subsection{Empirical Modeling}

\subsubsection{Lag Order Selection}

The VAR model has experienced decades of long-term development after it was proposed by Sims (1980), and has become one of the important models for analyzing the dynamic relationship structure between endogenous variables. The VAR model can examine the comprehensive and complex dynamic structural relationship between the added endogenous variables. It is an advantageous model for analyzing the complex dynamic relationship between China's EPU and stock market price. Next, by listing the parameter output results, impulse response function and variance decomposition to elaborate on the interaction between the two, which can help us to better understand the process of the interaction between china's EPU and stock market price, including the magnitude, direction and duration of the impact. Therefore, the next step is to construct a VAR model to analyze the dynamic relationship between the two variables in detail, first introduce the form of the VAR model. Referring to Tsay (2013), the

Table 6. Multivariate portmanteau test.

\begin{tabular}{cccc}
\hline $\boldsymbol{m}$ & $Q(\boldsymbol{m})$ & $\mathrm{df}$ & $\boldsymbol{p}$-value \\
\hline 1 & $279^{* * *}$ & 4 & $<0.01$ \\
2 & $517^{* * *}$ & 8 & $<0.01$ \\
3 & $727^{* * *}$ & 12 & $<0.01$ \\
4 & $913^{* * *}$ & 16 & $<0.01$ \\
5 & $1096^{* * *}$ & 20 & $<0.01$ \\
6 & $1254^{* * *}$ & 24 & $<0.01$ \\
\hline
\end{tabular}

Note: ${ }^{*}{ }^{* *},{ }^{* *}$ mean significant at the level of $10 \%, 5 \%$, and $1 \%$ respectively.
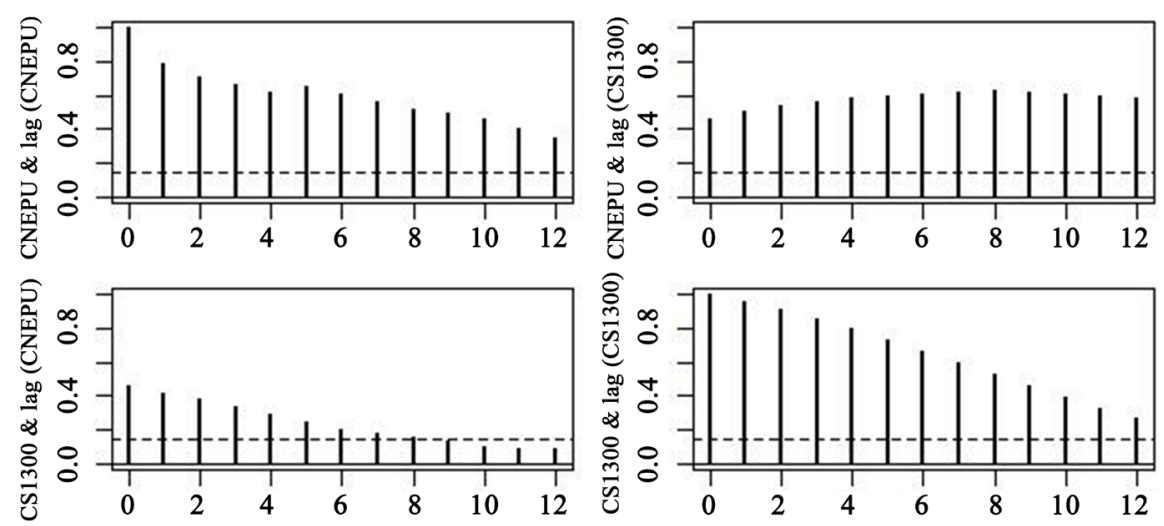

Figure 2. CCM figure. The dotted line represents the $95 \%$ confidence interval. 
lagging p-order $\operatorname{VAR}$ model (denoted as $\operatorname{VAR}(p)$ ) model vectorization form is:

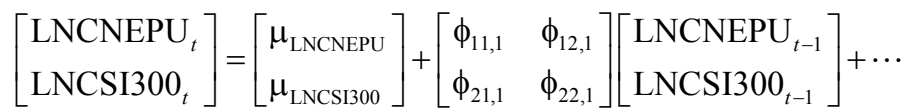

$$
\begin{aligned}
& +\left[\begin{array}{ll}
\phi_{11, p} & \phi_{12, p} \\
\phi_{21, p} & \phi_{22, p}
\end{array}\right]\left[\begin{array}{l}
\mathrm{LNCNEPU}_{t-p} \\
\mathrm{LNCSI}^{2} 00_{t-p}
\end{array}\right]+\left[\begin{array}{c}
\varepsilon_{\mathrm{LNCNEPU}, t} \\
\varepsilon_{\mathrm{LNCSS} 300, t}
\end{array}\right]
\end{aligned}
$$

Next, let

$$
\begin{gathered}
Y_{t}=\left[\begin{array}{c}
\mathrm{LNCNEPU}_{t} \\
{\mathrm{LNCSI} 300_{t}}
\end{array}\right], \mu=\left[\begin{array}{l}
\mu_{\mathrm{LNCNEPU}} \\
\mu_{\mathrm{LNCSI} 300}
\end{array}\right], \quad \phi_{1}=\left[\begin{array}{ll}
\phi_{11,1} & \phi_{12,1} \\
\phi_{21,1} & \phi_{22,1}
\end{array}\right], \\
\phi_{p}=\left[\begin{array}{ll}
\phi_{11, p} & \phi_{12, p} \\
\phi_{21, p} & \phi_{22, p}
\end{array}\right], \quad \varepsilon_{t}=\left[\begin{array}{l}
\varepsilon_{\mathrm{LNCNEPU}, t} \\
\varepsilon_{\mathrm{LNCSI} 300, t}
\end{array}\right]
\end{gathered}
$$

Therefore, the $\operatorname{VAR}(p)$ model can finally be transformed into matrix form

$$
Y_{t}=\mu+\phi_{1} Y_{t-1}+\cdots+\phi_{p} Y_{t-p}+\varepsilon_{t}
$$

where $\phi_{i}(i=1, \cdots, p)$ are the $2 \times 2$ matrix of the $\mathrm{i}$-th parameter to be estimated, $\varepsilon_{t}$ is the $2 \times 1$ random error column vector, and $p$ is the maximum lag order of the model, $\varepsilon_{t} \sim N(0, \Omega), \Omega$ is the $2 \times 2$ variance covariance matrix.

In the same way, the VAR model with lag 1 order (denoted as VAR (1)) is vectorized as:

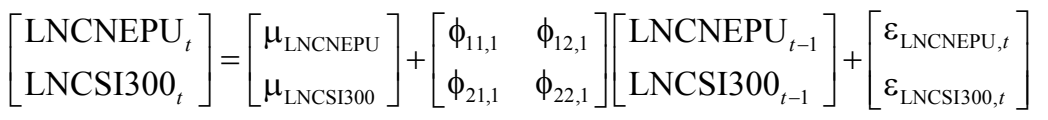

Put out $\mathrm{LNCNEPU}_{t}$ in the form of a linear equation:

$$
\text { LNCNEPU }_{t}=\mu_{\text {LNCNEPU }}+\phi_{11,1} \text { LNCNEPU }_{t-1}+\phi_{12,1} \text { LNCSI } 300_{t-1}+\varepsilon_{\text {LNCNEPU }, t} .
$$

Obviously, the left side of the equation is the period $t$ of LNCNEPU as the dependent variable, the right side is the lag 1 period variables of LNCNEPU and LNCSI300 respectively as the independent variable, and $\varepsilon_{\text {LNCNEPU, } t}$ is the random error term, which is assumed by the VAR model: between the lag variable and the random error term are irrelevant, and $\varepsilon_{1, t}, \varepsilon_{2, t} \sim\left(0, \sigma^{2}\right)$, $\operatorname{cov}\left(\varepsilon_{i, t}, \varepsilon_{j, t}\right)=0, i, j=1,2 . \phi_{11,1}, \phi_{12,1}$ are the two parameters to be estimated in the equation. It can be seen from the equation that when both LNCNEPU $_{t-1}$ and LNCSI $300_{t-1}$ change by one unit, LNCNEPU $_{t}$ changes $\phi_{11,1}+\phi_{12,1}$ on average. Similarly, the equation form of other variables of $\operatorname{VAR}(p)$ can be derived.

Table 7 is the optimal lag selection table for establishing the VAR model using LNCNEPU and LNCSI300. The output result of the information criterion with the lag order ranging from 0 to 4 shows that only the SC selected model has the optimal lag order of 1, LR, The optimal lag order of the FPE, AIC and HQ information criterion selection model is $2^{\text {nd }}$ order. Comprehensively considering the output results of the information criterion, the degree of model fitting and the complexity of the model, the lag $=2$ is finally selected as the lag order of the model, so the VAR (2) model is established. 


\subsubsection{Model Stationary Test}

In order to determine whether the effect of the model is up to the standard, the model stationary test is carried out. Figure 3 shows the output result of the model stationary test. It can be seen from Figure 3 that all the eigenvalues of the VAR (2) model fall within the unit circle, which shows that the model meets the requirements of model stationary, which shows that the output results of the VAR (2) model have strong explanations. Then output its parameter estimation results, impulse response function and variance decomposition to analyze the relationship in detail.

\subsubsection{Impulse Response Function Analysis}

In practical application, when analyzing the VAR model, it mainly studies the dynamic influence on the system when an error term changes, or when the model is impacted by a certain impact. This analysis method is called impulse response function analysis. Traditional impulse response analysis and variance decomposition generally use "orthogonal" pulses, and orthogonalization is usually achieved by Cholesky decomposition, but the result of Cholesky decomposition depends on the order of variables in the VAR model. In order to overcome the above shortcomings, this paper uses the generalized impulse response analysis proposed by Koop et al. (1996) to explore the impact of each endogenous

Table 7. Selection of lag order.

\begin{tabular}{ccccccc}
\hline Lag & LogL & LR & FPE & AIC & SC & HQ \\
\hline 0 & -92.81121 & NA & 0.009502 & 1.019475 & 1.054161 & 1.033531 \\
1 & 285.4106 & 744.2430 & 0.000170 & -3.004415 & $-2.900359^{*}$ & -2.962248 \\
2 & 292.4831 & $13.76467^{\star}$ & $0.000164^{*}$ & $-3.037453^{\star}$ & -2.864025 & $-2.967173^{\star}$ \\
3 & 296.1812 & 7.117947 & 0.000165 & -3.034207 & -2.791409 & -2.935816 \\
4 & 298.2334 & 3.905684 & 0.000168 & -3.013262 & -2.701093 & -2.886759 \\
\hline
\end{tabular}

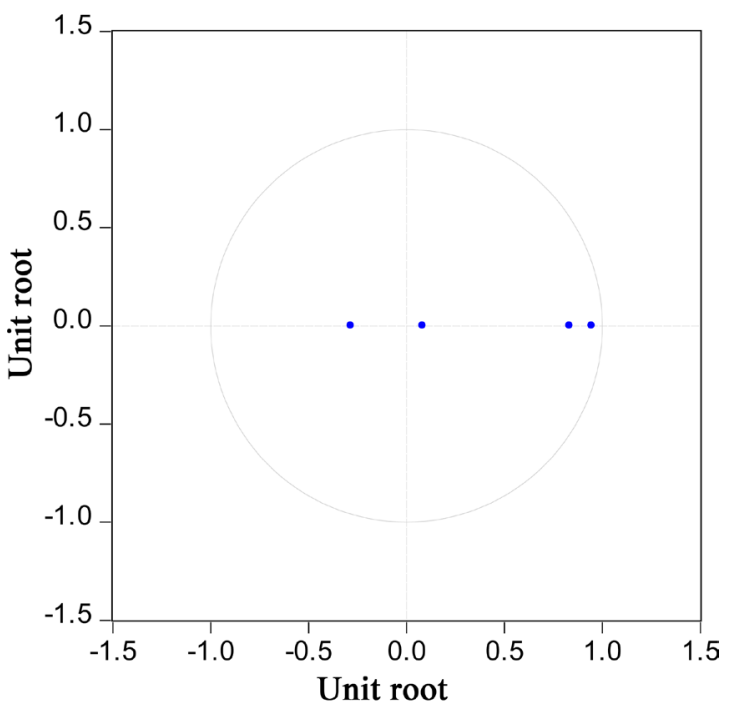

Figure 3. VAR (2) model stationary test. 
variable on other variables.

Let $\Phi(L)=I-\phi_{1} L-\phi_{2} L^{2}-\cdots-\phi_{P} L^{P}$ be the matrix polynomial of the lag operator, then Equation (1) can be written as:

$$
\Phi(L) Y_{t}=\varepsilon_{t}, \varepsilon_{t} \sim \text { i.i.d }(0, \Sigma) .
$$

Equation (2) is expressed as $\operatorname{VMA}(\infty)$ (Vector Moving Average) model:

$$
\begin{aligned}
y_{t} & =\left(I-\phi_{1} L-\cdots-\phi_{p} L^{p}\right)^{-1} \varepsilon_{t} \\
& =\left(I+A_{1} L+A_{2} L^{2}+\cdots+A_{q} L^{q}+\cdots\right) \varepsilon_{t}, t=p+1, \cdots, T
\end{aligned}
$$

Since there can be a contemporaneous correlation between the disturbance items, that is, the covariance matrix $\Sigma$ is not necessarily a diagonal matrix, then it will give $\varepsilon_{j t}$ an impact, and other elements in $\varepsilon_{t}$ will also change at the same time. At this time, an orthogonalized impulse response function is needed to solve this problem. A commonly used orthogonalization method is Cholesky decomposition, but the result strictly depends on the order of variables. The generalized impulse response function proposed by Koop et al. (1996) effectively overcomes the shortcomings of dependent variable order in Cholesky decomposition. First, calculate the changes of other elements in the same period caused by the change of $\varepsilon_{j t}$, then the shock at time $t$ is $\delta=E\left(\varepsilon_{t} \mid \varepsilon_{j t}=\delta_{j}\right)$, assuming that $\varepsilon_{t}$ follows a multivariate normal distribution, then

$$
\delta=E\left(\varepsilon_{t} \mid \varepsilon_{j t}=\delta_{j}\right)=\left(\sigma_{1 j}, \sigma_{2 j}, \cdots, \sigma_{k j}\right)^{\prime} \sigma_{j j}^{-1} \delta_{j}=\Sigma_{j} \sigma_{j j}^{-1} \delta_{j}
$$

Among them, $\sigma_{j j}=E\left(\varepsilon_{j t}^{2}\right), \Sigma_{j}=E\left(\varepsilon_{t} \varepsilon_{j t}\right)$ represents the $j$ th column element of the covariance matrix $\Sigma$, and the vector $y_{t+q}$ response caused by the impact of variable $j$ is:

$$
\begin{aligned}
\psi\left(q, \delta_{j}, \Omega_{t-1}\right) & =E\left(y_{t+q} \mid \varepsilon_{j t}=\delta_{j}, \Omega_{t-1}\right)-E\left(y_{t+q} \mid \Omega_{t-1}\right) \\
& =\theta_{q} \delta=\left(\frac{\theta_{q} \Sigma_{j}}{\sqrt{\sigma_{j j}}}\right)\left(\frac{\delta_{j}}{\sqrt{\sigma_{j j}}}\right), \quad q=0,1,2, \cdots
\end{aligned}
$$

In the formula, $\Omega_{t-1}$ represents the information collection of period $t-1$. In order to intuitively describe the time path of the impulse response, the impulse response function is plotted period by period within 10 periods.

Figure 4 shows the results of the impulse response analysis of LNCNEPU and LNCSI300. The diagonal line is the response process of two variables subjected to their own positive impact, and the off-diagonal line is the response process of two variables impacting each other. From the diagram, it is obvious that after the LNCNEPU is subjected to its own positive impact, the influence intensity is the largest in the initial stage, the influence coefficient is 0.15 , the positive influence intensity decreases gradually with the passage of time, and the influence intensity weakens to zero around the $10^{\text {th }}$ stage. This shows that the positive impact of economic policy uncertainty will stimulate the increase of economic policy uncertainty for a long time in the future. After the Chinese stock market price was positively impacted by its own, it rose positively, reaching the largest impact in 

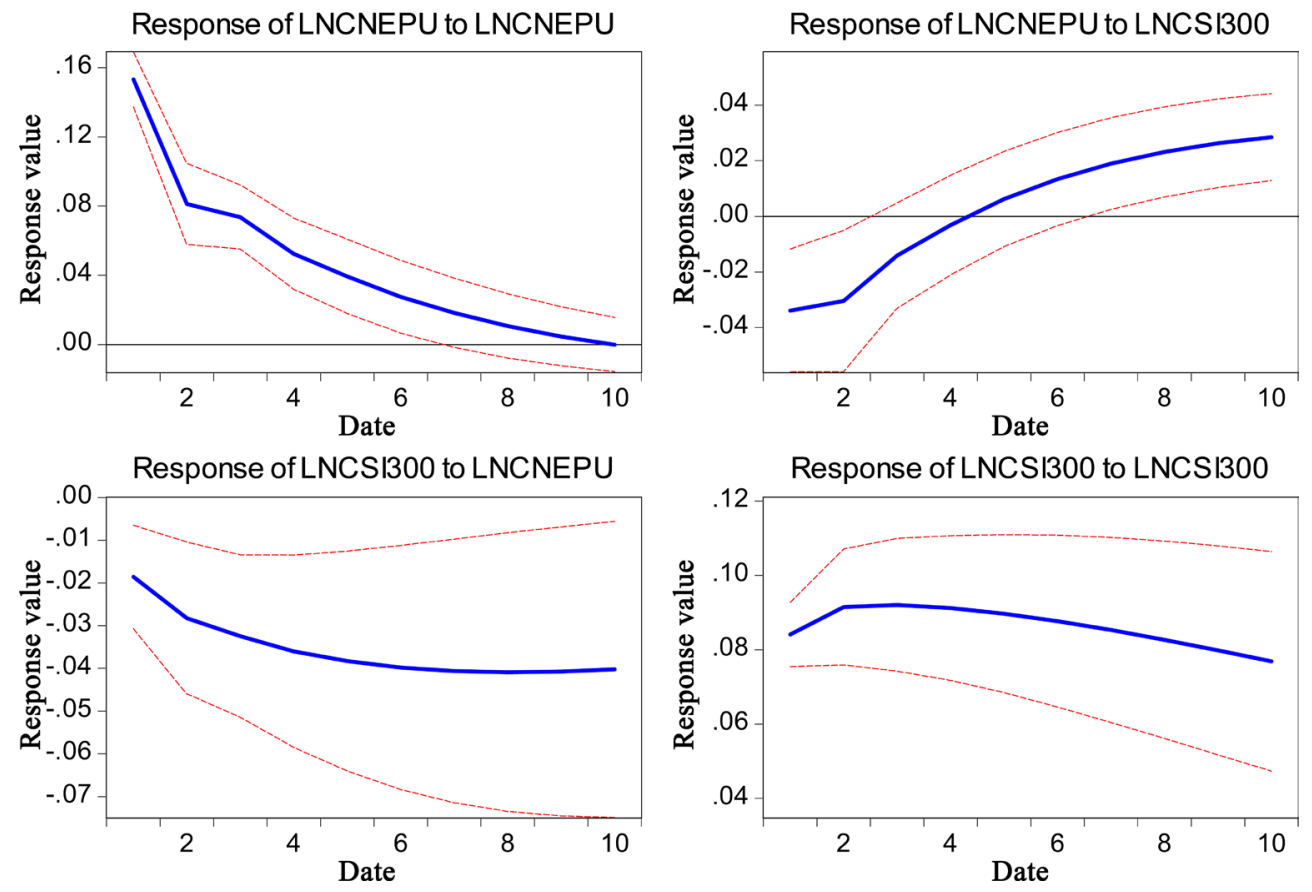

Figure 4. VAR (2) model impulse response function analysis result.

tensity in the second period, with an influence coefficient of 0.09 . Since then, the impact intensity has weakened, but basically remained at around 0.08 . This shows that the impact of price rise in China's stock market has a long-term lasting effect on the future stock market price. From the perspective of the impact of LNCSI300 on LNEPU, the positive impact of LNCSI300 on LNEPU is a dynamic process with a directional change. The first four phases of LNEPU showed a negative response, but in the fifth phase, the impact direction changed from negative to positive, and the influence intensity gradually increases, reaching stability around the tenth stage. This shows that the impact of rising prices in China's stock market will cause China's EPU to decline. The decline period lasts for 4 months. After that, the China's EPU begins to rise and reaches a plateau around the $10^{\text {th }}$ month. The positive impact of LNEPU has a negative impact on LNCSI300, and the impact is small at the beginning of the period. As time goes by, the impact effect gradually increases. After a 7-month enhancement period, the impact effect gradually stabilizes at around -0.04 . This shows that China's EPU has obvious lagging characteristics in its suppression of China's stock market prices, and its dynamics and long-term persistence are more obvious.

\subsubsection{Variance Decomposition}

Table 8 and Table 9 are the variance decomposition tables of LNCNEPU and LNCSI300, respectively. First of all, from the variance decomposition results of LNEPU, it can be seen that LNEPU has a high contribution rate to its own variance decomposition. In the $10^{\text {th }}$ period, there is still $91.63088 \%$. Although the variance contribution rate of LNCSI300 to LNEPU is less than $10 \%$, it still experienced a small margin increasing process. In the second period, the variance contribution 
Table 8. Variance decomposition of LNCNEPU.

\begin{tabular}{cll}
\hline Period & LNCNEPU & LNCSI300 \\
\hline 1 & $100.0000 \%$ & $0.000000 \%$ \\
2 & $99.45977 \%$ & $0.540232 \%$ \\
3 & $99.52846 \%$ & $0.471544 \%$ \\
4 & $99.36912 \%$ & $0.630878 \%$ \\
5 & $98.81559 \%$ & $1.184411 \%$ \\
6 & $97.88780 \%$ & $2.112198 \%$ \\
7 & $96.61999 \%$ & $3.380008 \%$ \\
8 & $95.09558 \%$ & $4.904419 \%$ \\
9 & $93.40354 \%$ & $6.596459 \%$ \\
10 & $91.63088 \%$ & $8.369120 \%$
\end{tabular}

Table 9. Variance decomposition of LNCSI300.

\begin{tabular}{ccc}
\hline Period & LNCNEPU & LNCSI300 \\
\hline 1 & $4.887794 \%$ & $95.11221 \%$ \\
2 & $7.371611 \%$ & $92.62839 \%$ \\
3 & $9.101935 \%$ & $90.89806 \%$ \\
4 & $10.67761 \%$ & $89.32239 \%$ \\
5 & $12.06254 \%$ & $87.93746 \%$ \\
6 & $13.28913 \%$ & $86.71087 \%$ \\
7 & $14.37004 \%$ & $85.62996 \%$ \\
8 & $15.32170 \%$ & $84.67830 \%$ \\
9 & $16.15877 \%$ & $83.84123 \%$ \\
10 & $16.89496 \%$ & $83.10504 \%$ \\
\hline
\end{tabular}

rate of LNCSI300 was $0.540232 \%$, and in the $10^{\text {th }}$ period, the variance contribution rate reached $8.36912 \%$. This shows that the overall impact of stock market price on the China's EPU is relatively small, but it also has a slight upward trend over time. From the variance decomposition results of LNCSI300, it can be seen that the contribution rate of LNCSI300 to its own variance has decreased significantly. In the first period, the contribution rate of LNCSI300 to its own variance was $95.11221 \%$, and in the tenth period, the contribution rate of variance decreased to $83.10504 \%$. From the variance decomposition results of LNEPU to LNCSI300, it can be seen that the contribution rate of LNEPU to LNCSI300 has experienced a substantial increase. In the first period, the contribution rate of LNEPU was only $4.887794 \%$. After experiencing a rapid rise, the contribution rate of LNEPU reached as high as $16.89496 \%$ in the $10^{\text {th }}$ phase. This shows that China's EPU has a very obvious impact on China's stock market prices, and the intensity of the impact has shown a sharp upward trend over time. 


\section{Robustness Test}

In order to test the robustness of the VAR (2) model based on the China's EPU and stock market price, the Shanghai and Shenzhen 300 Index (CSI300), a proxy indicator of China's stock market price used in the previous article, was replaced by the Shanghai Stock Exchange Composite Index (SZ). Repeat the above test, the optimal lag order is still selected as order 2. The results of the Granger causality test are shown in Table 10. The results show that after replacing the Shanghai and Shenzhen 300 Index (CSI300) with the Shanghai Stock Exchange Index (SZ), China's EPU and the stock market price are still Granger causes for each other.

Figure 5 shows the impulse response trend of the VAR (2) model established after replacing the Shanghai and Shenzhen 300 Index, a proxy indicator of Chinese stock market prices, with the Shanghai Stock Exchange Index. It can be clearly seen from the diagram that the direction of impulse response between China's EPU and the stock market price is completely consistent with the trend mentioned above, and the impact degree is different, but the difference is not significant. Further, through the robustness analysis of the variance decomposition

Table 10. Granger causality test.

\begin{tabular}{ccc}
\hline Null Hypothesis: & F-Statistic & Prob. \\
\hline LNSZ does not Granger Cause LNCNEPU & $9.81368^{\star * \star}$ & 0.0020 \\
LNCNEPU does not Granger Cause LNSZ & $6.43167^{\star *}$ & 0.0120 \\
\hline
\end{tabular}

Note: ${ }^{*}{ }^{* *},{ }^{* *}$ mean significant at the level of $10 \%, 5 \%$, and $1 \%$ respectively.
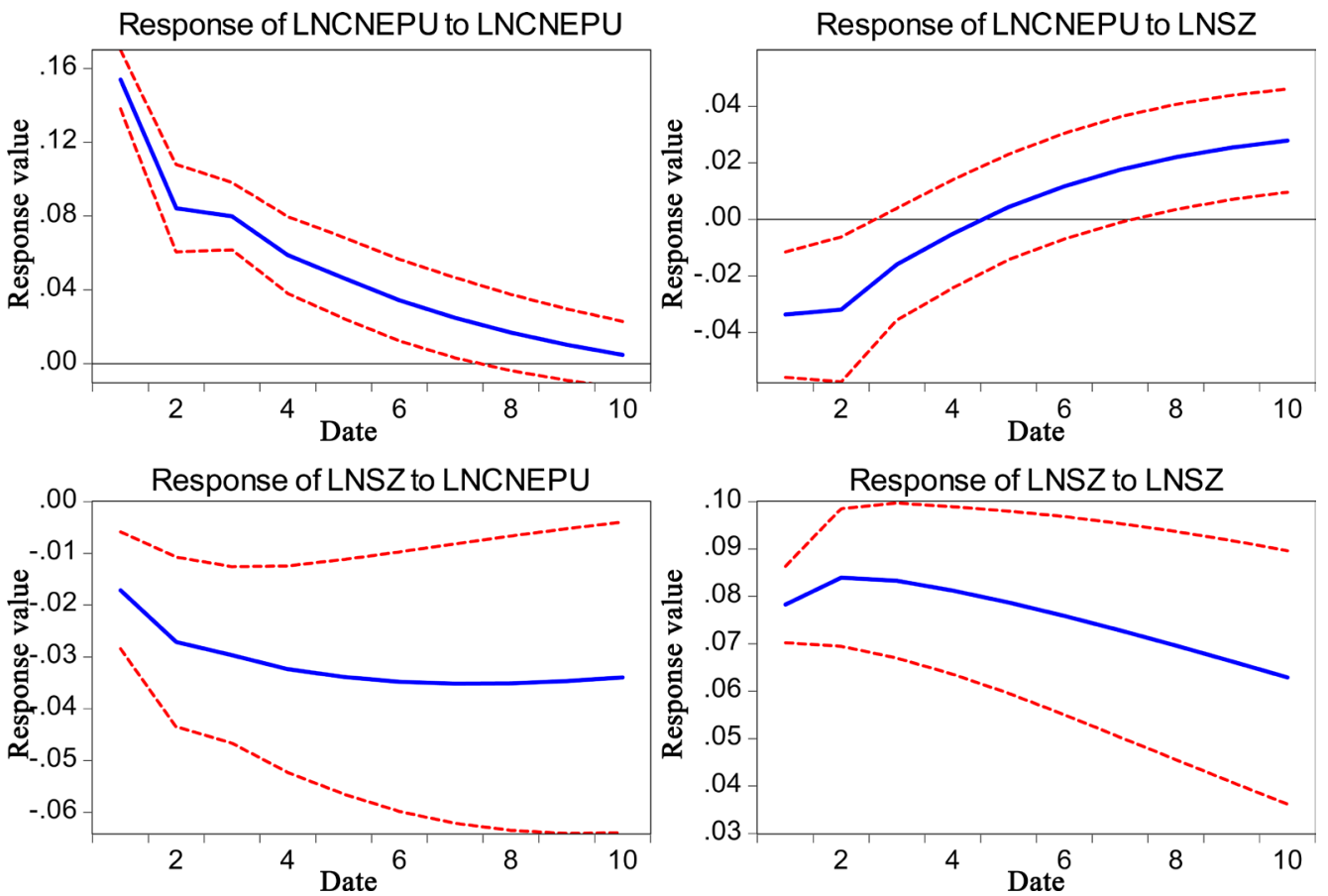

Figure 5. The impulse response trend of the VAR (2) model that replaces the Shanghai and Shenzhen 300 Index with the Shanghai Stock Exchange Index. 
results in Table 11 and Table 12, compared with the previous variance decomposition results, it can be seen that the variance decomposition results of LNCNEPU and LNSZ are very similar to the previous results. Therefore, it can be considered that the model has passed the robustness test.

\section{Conclusion}

This paper uses the data of China's economic policy uncertainty and stock market price from January 2005 to October 2020 to analyze their fundamentals, and carries out cointegration test, Granger causality test and so on. Based on the above test, the VAR model is established, the impulse response trend and variance decomposition of the two are analyzed, and the robustness test is carried out. This paper draws the following conclusions: first, there is a long-term cointegration relationship between China's EPU and stock market price. By observing the timing diagram of the two, we can see that there are similar fluctuations

Table 11. Variance decomposition of LNCNEPU.

\begin{tabular}{ccc}
\hline Period & LNCNEPU & LNSZ \\
\hline 1 & $100.0000 \%$ & $0.000000 \%$ \\
3 & $99.38264 \%$ & $0.617364 \%$ \\
4 & $99.48092 \%$ & $0.519081 \%$ \\
5 & $99.37339 \%$ & $0.626614 \%$ \\
6 & $98.89495 \%$ & $1.105049 \%$ \\
7 & $98.06549 \%$ & $1.934513 \%$ \\
8 & $96.90513 \%$ & $3.094865 \%$ \\
9 & $95.48852 \%$ & $4.511478 \%$ \\
10 & $93.89534 \%$ & $6.104662 \%$ \\
\hline
\end{tabular}

Table 12. Variance decomposition of LNSZ.

\begin{tabular}{ccc}
\hline Period & LNCNEPU & LNSZ \\
\hline 1 & $4.786435 \%$ & $95.21356 \%$ \\
2 & $7.760040 \%$ & $92.23996 \%$ \\
3 & $9.381709 \%$ & $90.61829 \%$ \\
4 & $10.88670 \%$ & $89.11330 \%$ \\
5 & $12.19591 \%$ & $87.80409 \%$ \\
6 & $13.37075 \%$ & $86.62925 \%$ \\
8 & $14.41802 \%$ & $85.58198 \%$ \\
9 & $15.35240 \%$ & $84.64760 \%$ \\
10 & $16.18436 \%$ & $83.81564 \%$ \\
\hline
\end{tabular}


in the research stage. The preliminary explanation has certain correlation. By Johansen cointegration test, it is found that there is a long-term cointegration relationship between the two, and the Granger causality test shows that the two are Granger causality. The multivariate portmanteau test showed that there are obvious autocorrelation and cross-correlation between CNEPU and CSI300, and the dynamic correlation was further analyzed by using CCM method. The results showed that there was a long-term correlation between CNEPU and CSI300. The second research content is to establish a VAR model and analyze the conduction mechanism between the two through the results of impulse response and variance decomposition. The results show that the increasing China's EPU will have a depressing effect on China's stock market prices, and it will have a certain lag and long-term persistence. Conversely, the impact of China's stock market prices on the China's EPU has directional changes over time. The impact of China's stock market price increases will cause the China's EPU to decrease. The decline period will last for 4 months, after which it starts to rise and stabilizes in the $10^{\text {th }}$ month. On the whole, the impact of China's EPU on stock market prices is very obvious, and the intensity of the impact has shown a significant increase over time, but the impact of China's stock market prices on EPU is relatively weaker.

Starting from the above analysis, the following suggestions are put forward: first of all, we should pay attention to the transmission of economic policy formulation to the sentiment of the stock market. Since the measurement of policy uncertainty mainly comes from media news reports, it is necessary to regulate the accuracy and objectivity of social media reports on economic policies and related information disclosure. At the same time, pay attention to maintaining the continuity of economic policies, thereby reducing the impact of economic policies on the stability of the stock market. Secondly, investors obviously have certain irrational behavior characteristics due to the influence of psychological factors. Therefore, it is necessary to further cultivate the stable market function of institutional investors. Especially in the period of market downturn, the short-selling mechanism or the risk management function of other financial derivatives transactions should be fully utilized to guide and reduce the impact of investors' irrational behavior on the stability of the securities market.

Limitations of this paper and future research direction: First, this paper directly carries out empirical analysis under the set model to a certain extent, which can improve the lack of evidence in the selection of econometric models in the future. Second, the dynamic relationship between China's EPU and the stock market can be analyzed through a variety of dynamic analysis methods.

\section{Conflicts of Interest}

The authors declare no conflicts of interest regarding the publication of this paper.

\section{Funding}

This paper was supported by the National Natural Science Foundation of China 
(No.71963008, No.71601048); The Joint cultivation project of Guangxi Natural Science Foundation (No.2018GXNSFAA294131); and the Innovation Project of Guangxi Graduate Education (No.YCSW2020175).

\section{References}

Antonakakis, N., Chatziantoniou, I., \& Filis, G. (2013). Dynamic Co-Movements of Stock Market Returns, Implied Volatility and Policy Uncertainty. Economics Letters, 120, 87-92. https://doi.org/10.1016/j.econlet.2013.04.004

Bahmani-Oskooee, M., \& Saha, S. (2019). On the Effects of Policy Uncertainty on Stock Prices. Journal of Economics and Finance, 43, 764-778. https://doi.org/10.1007/s12197-019-09471-x

Baker, S. R., Bloom, N., \& Davis, S. J. (2016). Measuring Economic Policy Uncertainty. The Quarterly Journal of Economics, 131, 1593-1636. https://doi.org/10.1093/qje/qjw024

Bernal, O., Gnabo, J. Y., \& Guilmin, G. (2016). Economic Policy Uncertainty and Risk Spillovers in the Eurozone. Journal of International Money and Finance, 65, 24-45. https://doi.org/10.1016/j.jimonfin.2016.02.017

Bloom, N. (2009). The Impact of Uncertainty Shocks. Econometrica, 77, 623-685. https://doi.org/10.3982/ECTA6248

Chen, G. J., Zhang, R. Z., \& Zhao, X. Q. (2017). Policy Uncertainty, Consumer Behavior and Stock Asset Pricing. World Economy, 40, 116-141.

Chiang, T. C. (2019). Economic Policy Uncertainty, Risk and Stock Returns: Evidence from G7 Stock Markets. Finance Research Letters, 29, 41-49. https://doi.org/10.1016/j.frl.2019.03.018

Dzielinski, M. (2012). Which News Resolves Asymmetric Information? SSRN Electronic Journal, 1-36. https://doi.org/10.2139/ssrn.2146698

Goodell, J. W., \& Vähämaa, S. (2013). US Presidential Elections and Implied Volatility: The Role of Political Uncertainty. Journal of Banking \&. Finance, 37, 1108-1117. https://doi.org/10.1016/j.jbankfin.2012.12.001

Huang, Y., \& Luk, P. (2019). Measuring Economic Policy Uncertainty in China. China Economic Review, 59, Article ID: 101367. https://doi.org/10.1016/j.chieco.2019.101367

Jia, D., Sun, X., \& Guo, R. (2019). Monetary Policy Announcements, Policy Uncertainties and the Pre-Announcement Premium Effect in the Stock Market-Evidence from the Chinese Market. Financial Research, 469, 76-95.

Koop, G., Pesaran, M. H., \& Potter, S. M. (1996). Impulse Response Analysis in Nonlinear Multivariate Models. Journal of Econometrics, 74, 119-147.

https://doi.org/10.1016/0304-4076(95)01753-4

Li, X. L., Balcilar, M., Gupta, R., \& Chang, T. (2016). The Causal Relationship between Economic Policy Uncertainty and Stock Returns in China and India: Evidence from a Bootstrap Rolling Window Approach. Emerging Markets Finance and Trade, 52, 674689. https://doi.org/10.1080/1540496X.2014.998564

Li, X. M., \& Peng, L. (2017). US Economic Policy Uncertainty and Co-Movements between Chinese and US Stock Markets. Economic Modelling, 61, 27-39. https://doi.org/10.1016/j.econmod.2016.11.019

Lin, J. H., Li, X., \& Li, H. (2014). Empirical Study of Chinese Economic Policy Uncertainty and Asset Pricing. Chinese Management Science, No. 22, 222-226.

Pástor, L., \& Veronesi, P. (2013). Political Uncertainty and Risk Premia. Journal of Financial Economics, 110, 520-545. https://doi.org/10.1016/j.jfineco.2013.08.007 
Sialm, C. (2005). Tax Changes and Asset Pricing: Time-Series Evidence. American Economic Review, 99, 1356-1383. https://doi.org/10.1257/aer.99.4.1356

Sims, C. A. (1980). Macroeconomics and Reality. Econometrica, 48, 1-48. https://doi.org/10.2307/1912017

Tsay, R. S. (2005). Analysis of Financial Time Series. Hoboken, NJ: John Wiley \& Sons. https://doi.org/10.1002/0471746193

Tsay, R. S. (2013). Multivariate Time Series Analysis: With $R$ and Financial Applications. Hoboken, NJ: John Wiley \& Sons.

Wang, H., Song, D. H., \& Chen, L. H. (2018). The Uncertainty of Economic Policy and Stock Returns. Finance Quarterly, 12, 1-20.

Wu, T. P., Liu, S. B., \& Hsueh, S. J. (2016). The Causal Relationship between Economic Policy Uncertainty and Stock Market: A Panel Data Analysis. International Economic Journal, 30, 109-122. https://doi.org/10.1080/10168737.2015.1136668 